\title{
Characterization of changes in global gene expression in the hearts and kidneys of transgenic mice overexpressing human angiotensin-converting enzyme 2
}

\author{
Su Hae Lee ${ }^{1}$, Seung Wan Jee ${ }^{2}$, Dae Youn Hwang ${ }^{3^{*}}$ (D) and Jong Koo Kang ${ }^{4^{*}}$
}

\begin{abstract}
Human angiotensin-converting enzyme 2 (hACE2) has recently received a great attention due to it play a critical role as SARS-CoV receptor in the infection of human body. However, no further analysis for gene regulation has been performed in target tissues of model mice during hACE2 overproduction. To characterize changes in global gene expression in the hearts and kidneys of rtTA/hACE2 double transgenic (dTg) mice in response to hACE2 overexpression, total RNA extracted from these tissues from dTg mice after doxycycline (Dox) treatment was hybridized to oligonucleotide microarrays. Briefly, dTg mice were generated by cross-mating pa-MHC/rtTA Tg mice with pTRE/hACE2 Tg mice. The expression level of hACE2 protein was determined to be high in hearts, kidneys, and brains of dTg mice, whereas lung, liver, and testis tissues expressed low levels. The level of hACE2 was significantly enhanced in hearts and kidneys of the Dox+dTg group compared to that in Vehicle+dTg mice although consistent levels of mouse ACE2 (mACE2) remained in the same tissues. Based on the microarray analysis of heart tissue, 385 genes were differentially expressed, including 168 upregulated and 217 downregulated, when comparing non-Tg and Vehicle+dTg mice, whereas 216 genes were differentially expressed, including 136 upregulated and 80 downregulated, between Vehicle+dTg and Dox+dTg mice. In the kidneys, 402 genes were differentially expressed, including 159 upregulated and 243 downregulated, between non-Tg and Vehicle+dTg mice. Dox-treated dTg mice exhibited the differential expression of 4735 genes including 1636 upregulated and 3109 downregulated. Taken together, these findings suggested that several functional groups and individual genes can be considered biomarkers that respond to hACE2 overexpression in dTg mice. Moreover, our results provided a lot of useful information to predict physiological responses when these dTg mice are applied as a susceptible model for novel coronavirus (SARS-CoV, COVID-19) in both vaccine and drug development.
\end{abstract}

Keywords: Human ACE2, Transgenic mice, a-MHC, C57BL/6NKorl, Microarray, Coronavirus

\footnotetext{
*Correspondence: dyhwang@pusan.ac.kr; jkkang@cbnu.ac.kr

${ }^{3}$ Department of Biomaterials Science, College of Natural Resources \& Life Science/Life and Industry Convergence Research Institute, Pusan National University, Miryang 50463, South Korea

${ }^{4}$ College of Veterinary Medicine, Chungbuk National University, Chungju 28644, South Korea

Full list of author information is available at the end of the article
}

(c) The Author(s). 2020 Open Access This article is licensed under a Creative Commons Attribution 4.0 International License, which permits use, sharing, adaptation, distribution and reproduction in any medium or format, as long as you give appropriate credit to the original author(s) and the source, provide a link to the Creative Commons licence, and indicate if changes were made. The images or other third party material in this article are included in the article's Creative Commons licence, unless indicated otherwise in a credit line to the material. If material is not included in the article's Creative Commons licence and your intended use is not permitted by statutory regulation or exceeds the permitted use, you will need to obtain permission directly from the copyright holder. To view a copy of this licence, visit http://creativecommons.org/licenses/by/4.0/ The Creative Commons Public Domain Dedication waiver (http://creativecommons.org/publicdomain/zero/1.0/) applies to the data made available in this article, unless otherwise stated in a credit line to the data. 


\section{Introduction}

Angiotensin-converting enzyme 2 (ACE2) is the first known human homolog of ACE and was cloned from a human heart failure and human lymphoma cDNA library [1, 2]. ACE2 might play a pivotal role as a new element of the renin angiotensin system (RAS) by reducing Ang II and increasing levels of Ang1-7 [3-6] and is distributed in a wide variety of tissues, including the brain, lung, heart, liver, kidney, and testis, as well as most cardiovascular-relevant tissues [7-11]. In the heart, myocardial infarction increases ACE2 expression, which is localized to the vascular endothelium, smooth muscle, and cardiomyocytes of both rats and humans [12]. ACE2 participates in the regulation of blood pressure and cardiac and renal functions and is associated with major cardiac and renal pathophysiological processes. Especially, it has been reported that $A C E 2$ gene expression is upregulated in humans with heart failure [13]. It is also predominantly expressed in the proximal tubular brush border, distal tubules, and glomerular epithelial cells in the kidneys of humans, rats, and mice [14-17]. The colocalization of ACE2 with Ang1-7 in renal tubules reveals the functional ability of Ang1-7 to counteract the action of Ang II, and these vasodilator peptides might be a critical link, mediating regulatory feedback between ACE and ACE2 [18-20]. Although the function of ACE2 in the brain is poorly understood, there is considerable evidence of a role for Ang1-7. Previous studies have shown that Ang1-7 is an important neuromodulator of cardiac baroreflex mechanisms [21]. The ACE1/2 and neutral endopeptidase or neprilysin (NEP) are zinc metallopeptidases [22]. However, more recently, ACE2 has aroused considerable attention as a receptor for the coronavirus that causes severe acute respiratory syndrome and a protector against severe lung failure [23, 24].

In the past decade, functional studies on hACE2 have continued using transgenic animals to clarify the mechanism related to heart and renal failures, as well as other pathophysiological conditions. First, in knockout mice, the genetic disruption of ACE2 leads to severe cardiac contractile dysfunction, increases in Ang II levels, the upregulation of hypoxia-induced genes, and decreases in ACE2 transcript and protein levels in the heart [25]. However, it is necessary to additionally study the effects related to hACE2 expression levels to clarify whether increased levels can have a beneficial effect on cardiac and renal functions.

Myosin heavy chain (MHC), which is found in the contractile apparatus and is a major protein, is composed of two heavy chains and four light chains. In the cardiac muscle, two distinct $M H C$ genes, which encode $\alpha$ - and $\beta-M H C$ isoforms, have been identified [26].
Previously, the $\alpha-M H C$ gene promoter was used to direct tissue- and developmental-specific expression of the transgene in transgenic ( $\mathrm{Tg}$ ) animals [27]. Further, there are many transcriptional regulation systems, and tetracycline regulatory systems have been widely used for conditional gene expression. The tetracycline-controlled transactivator (tTA) is generated by fusing the DNAbinding domain of the tetracycline-resistance operon (TetR) encoded by Tn10 of E. coli with the transcriptional activation domain of VP16 of herpes simplex virus [28]. There are two basic variants of this, tTA and reverse tTA (rtTA) systems. To compensate for the tTA system, which requires long-term administration of doxycycline (dox) for induction of the transgene, the other inducible system, namely rtTA (Tet-On system), has been developed. This system requires two DNA constructs, a transcriptional regulatory unit and the responsive element tet $O$ sequences linked to a $\mathrm{P}_{\mathrm{CMV}}$-derived target gene. In the presence of dox, rtTA binds tet $O$ sequences and $\mathrm{P}_{\mathrm{CMV}}$, which activates the target gene. In contrast, rtTA does not bind tet $O$ and the target gene is not transcribed in the absence of dox [29, 30]. The doxinducible gene regulatory system allows for the tight and adjustable control of a transgene of interest to study organ development and disease pathogenesis. Previously, Tg rats expressing human $A C E$ under the control of the rat cardiac myosin light chain 2 (MLC2) promoter and Tg mice expressing human $A C E 2$ under the control of the mouse cardiac $\alpha-M H C$ promoter have been generated [31, 32]. These Tg mice had a high incidence of sudden death and rhythmic disturbances with sustained ventricular tachycardia including terminal ventricular fibrillation and heart block. However, in surviving older mice, spontaneous downregulation of the ACE2 transgene was observed, which was associated with the restoration of nearly normal conduction, rhythm, and connexin expression. Because sudden death occurs earlier in higher-expressing transgenic lines, a promoter that can be regulated, such as the Tet-On or Off system, might be useful to examine cardiac and renal pathophysiology at the basal level. The aim of this study was to characterize changes in global gene expression in the hearts and kidneys of dTg mice, created with $\mathrm{p} \alpha-\mathrm{MHC} /$ rtTA and pTRE/hACE2 vectors, in response to the overproduction of hACE2 protein.

\section{Materials and methods}

\section{Construction of dox-inducible vector system}

First, $p \alpha-M H C / r t T A$ was constructed by fusing the $r t T A-M 2$ gene with the $\alpha-M H C$ promoter (Gene bank accession NO. U71441). The pUHrT62-1 was a gift from Dr. Wolfgang Hillen at the University of Heidelberg, Germany [33]. This plasmid contains a mutagenized $r t T A-M 2$ fragment harboring the S12G, E19G, and 
A56P mutations. The $\alpha-M H C$ sequence was amplified by PCR, with the genomic DNA as a template, which was isolated from the tail of BDF2 mice. The following primers were used for the amplification: the sense primer, 5'-CTCCT TCCTT GTTGC ATCTT CC-3' (corresponding to nucleotides 2,278-2,299 of $\alpha-M H C$ ), and the antisense primer, 5'-CAGGA GGAAG ATGGA GAAGA CAG-3' (corresponding to nucleotides 4,578$4,600$ of $\alpha-M H C)$. The amplified $\alpha-M H C$ product was cloned into $p G E M-T(p \alpha-M H C-T)$. The $\alpha-M H C$ fragment obtained by the digestion of $p \alpha-M H C-T$ with $S a c \mathrm{I}$ and SacII was cloned into pUHDrtTA2S-M2-splice, in which the human $C M V$ promoter has been eliminated via digestion with XhoI and SacII (pa-MHC/rtTA). Second, $p T R E / h A C E 2$ was constructed by inserting the hACE2 gene into the NotI site within the multiple cloning site of $p$ TRE2hyp (Clontech Laboratories Inc., Mountain View, CA, USA). The $p T R E 2 h y p$ gene contains a tet response element (TRE), which consists of seven copies of the 19-bp tetracycline operator sequence (tetO) and hygromycin resistance genes. The hACE2 cDNA was amplified by PCR, using a sense primer (5'-GACGA TGTCA AGCTC TTCCT G-3') with nucleotides 100120 and an antisense primer (5'-GCCTA cagat cttct tcaga aataa gtttt tgttc AAAGG TCTGA ACATC ATCAG TG-3'; lowercase letter, $c$ - $m y c$ tag) with nucleotides 2,494-2,521 based on $h A C E 2$ (Gene bank accession NO. NM_021804). Full-length RNA was used as the template, which was isolated from HEK-293 cells (ATCC CRL-1573). The amplified $h A C E 2$ product was inserted into $p G E M-T$ (phACE2-T; Fig. 1a and b).

\section{Maintenance of experimental animals}

The experimental protocol for $\mathrm{dTg}$ mice was carefully reviewed based on ethical and scientific care guidelines and approved by the National Institute of Food and Drug Safety Evaluation-Institutional Animal Care and Use Committee (NIFDS-IACUC; Approval No. NITR0631). All C57BL/6NKorl and DBA/2Korl mice at 6 weeks of age were provided by the Department of Laboratory Animals Resources in NIFDS (Cheongju, Korea). All mice used in this study were provided with ad libitum access to water and an irradiated standard chow diet (Purina Mills Inc., Pyeongtaek, Korea). Mice were housed in cages under specified pathogen free (SPF) condition under a strict light cycle (light on at 06: $00 \mathrm{~h}$ and off at 18:00 h). All mice were handled in an accredited NIFDS animal facility in accordance with the AAALAC International Animal Care policies (Accredited Unit-the Ministry of Food and Drug Safety: Unit Number-001492).

\section{Production of rtTA/hACE2 dTg mice}

For the first lineage of Tg mice, a linear 5.8-kb $\alpha-M H C /$ $r t T A$ fragment was microinjected into the pronucleus of fertilized eggs of BDF1 mice, which had been obtained by mating C57BL/6NKorl (males) and DBA2Korl (females) mice. For the second lineage of Tg mice, the linear 7.9-kb fragment of TRE/hACE2 was microinjected into the pronucleus of a fertilized embryo after dilution to a concentration of $4 \mathrm{ng} / \mu \mathrm{L}$. Microinjection was performed using microscopy (Nikon, Tokyo, Japan) and a micromanipulator (Narishge, Tokyo, Japan). Each Tg line was established by back crossing the founder mice with a parental strain of C57BL/6NKorl mice. The dTg mice were obtained by crossing the first lineage of $\alpha$ $M H C / r t T A \mathrm{Tg}$ mice with the second lineage of TRE/ hACE2 Tg mice. The single and double Tg founder mice were back crossed onto the parental strain of the C57BL/6NKorl background to establish homogenous Tg lines.

The transgene was identified by DNA-PCR analysis of the genomic DNA isolated from the tail of 4-week-old founder mice. The precipitated DNA was separated by centrifugation at 15,000 rpm for $10 \mathrm{~min}$. After washing in $700 \mu \mathrm{L} 70 \% \mathrm{Et}-\mathrm{OH}$, DNA was dried for $15 \mathrm{~min}$ and dissolved in $200 \mu \mathrm{L}$ of distilled water. The $\alpha-M H C / r t T A$ gene was amplified as a template using the sense primer (5'-CTGTC TTCTC CATCT TCCTC CTG-3') with a complementary $\alpha-M H C$ promoter ranging from 4578 to 4600 nucleotides and an antisense primer ( $5^{\prime}$-CAGGG TAGGC TGCTC AACTC-3') with a complementary rtTA gene ranging from 888 to 908 nucleotides. The TRE/hACE2 gene was also synthesized as a template using a sense primer (5'-GACGA TGTCA AGCTC TTCCT G-3') and antisense primer (5'-CATAT AATGG CCTCA GCTGC-3') with a complementary $h A C E 2$ gene ranging from 100 to 120 and from 625 to 644 nucleotides, respectively. PCR amplification was carried out in a Thermal cycler (Perkin Elmer, Norwalk, CT, USA) using the following cycling conditions: one cycle: $94^{\circ} \mathrm{C}, 4 \mathrm{~min} ; 27$ cycles: $30 \mathrm{~s}$ at $94^{\circ} \mathrm{C}$, $1 \mathrm{~min}$ at $62^{\circ} \mathrm{C}$, and $45 \mathrm{~s}$ at $72^{\circ} \mathrm{C}$; one elongation step of $7 \mathrm{~min}$ at $72^{\circ} \mathrm{C}$.

\section{Doxycycline (dox) treatment}

The $\mathrm{dTg}$ mice were distributed into two groups (3-5 mice per group), namely vehicle and Dox treatment. Drinking water containing $2 \mathrm{mg} / \mathrm{mL}$ Dox (Sigma-Aldrich Co., St. Louis, MO, USA) was administered to mice of the Dox-treated group for 4 weeks, whereas tap water was administrated to mice of the vehicle group for the same period. 


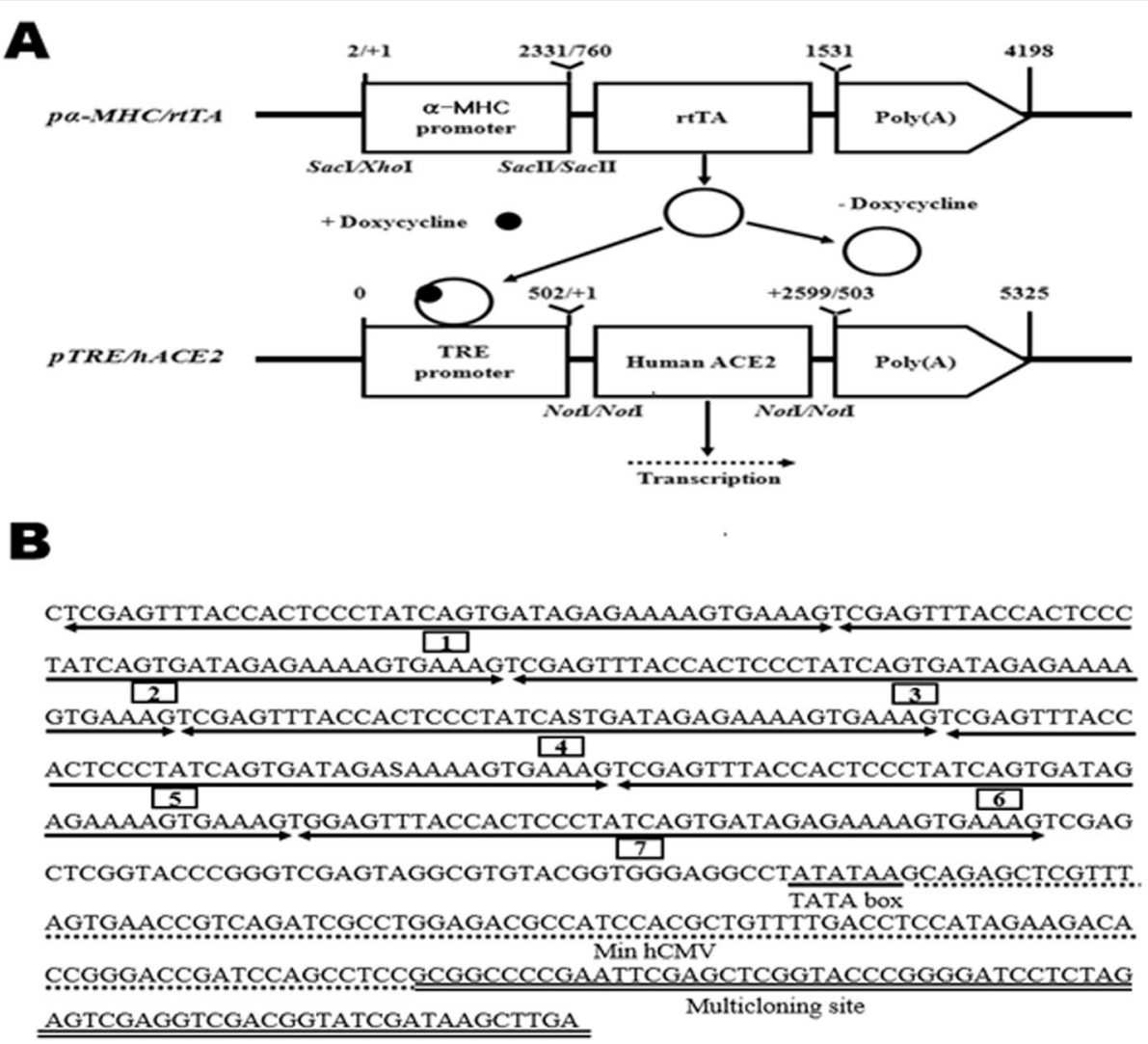

C.

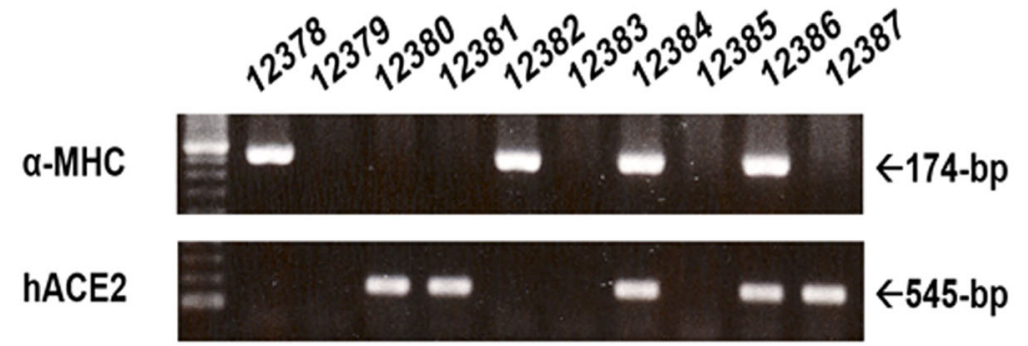

Fig. 1 Reverse tet promoter-controlled transactivator (rtTA) and hACE2 vectors and identification of $a-M H C / r t T A$ and TRE/hACE2 transgenes. a Construction of the pa-MHC/rtTA and pTRE/hACE2 expression vectors. rtTA and hACE2 (human ACE2) were placed under the control of the $a-M H C$ and TRE promoter, respectively. Two independent lineages of transgenic (Tg) mice were produced and mated together to obtain the double Tg (dTg) mice. In the dTg mice, the expression of the hACE2 is induced by rtTA in the presence of doxycycline (Dox). The arrow (--->) indicates transcription. $\mathbf{b}$ Features of the tet response element (TRE) promoter sequence. The TRE promoter is contained with seven copies of the tetO sequence, a TATA box, and an hCMV promoter. c The genomic DNA was isolated from the tail of the founder mouse, and the 174-bp and 545bp products were shown in the dual transgenic mice carrying the a-MHC/rtTA and TRE/hACE2 transgenes, respectively

\section{Western blot analysis}

The brain, heart, lung, liver, kidney, and testis tissues were collected from mice of subset groups and homogenized with $1 \%$ nnonidet P-40 in $15 \mathrm{mM} \mathrm{NaCl}, 10 \mathrm{mM}$ tris $\mathrm{HCl}$, and $1 \mathrm{mM}$ EDTA supplemented with a protein inhibitor mixture (Roche, Basel, Switzerland), which was followed by centrifugation at $4^{\circ} \mathrm{C}$ for $15 \mathrm{~min}$. For western blot analysis, the proteins were separated by electrophoresis using a 4-20\% gradient SDS-polyacrylamide gel for
$2 \mathrm{~h}$ and then transferred to a nitrocellulose membrane with transfer buffer containing $25 \mathrm{mM}$ tris-base, 192 $\mathrm{mM}$ glycine, and $20 \%$ methanol at $45 \mathrm{~V}$ for $2 \mathrm{~h}$. Membranes were blocked with $3 \%(\mathrm{w} / \mathrm{v})$ non-fat dried milk in PBS $\left(137 \mathrm{mM} \mathrm{NaCl}, 2.7 \mathrm{mM} \mathrm{KCL}, 10 \mathrm{mM} \mathrm{Na} \mathrm{N}_{2} \mathrm{HPO}\right.$ and $\left.2 \mathrm{mM} \mathrm{KH_{2 }} \mathrm{PO}_{4}\right)$ solution containing $0.05 \%$ tween-20 (Sigma-Aldrich Co.). The membrane was washed with PBS and incubated overnight $4^{\circ} \mathrm{C}$ with primary antibodies as follows: anti-human ACE2 (Santa Cruz 
Biotechnology Inc., Santa Cruz, CA, USA), anti-human ACE (Santa Cruz Biotechnology Inc.), and anti- $\alpha$-tubulin (Sigma-Aldrich Co.). After washing, each antigen-antibody complex was visualized with biotinylated secondary antibodies as follows: goat anti-mouse IgG $(\mathrm{H}+\mathrm{L}) \mathrm{HRP}-$ conjugated antibody, rabbit anti-goat IgG $(\mathrm{H}+\mathrm{L})$ HRPconjugated antibody, and goat anti-rabbit $\operatorname{IgG}(\mathrm{H}+\mathrm{L})$ HRP-conjugated antibody (Zymed Laboratories Inc., San Francisco, CA, USA) at a 1:1000 dilution in PBS buffer containing 3\% non-fat dried milk/PBS buffer at room temperature for $1 \mathrm{~h}$. Immunoreactive proteins were detected by an enhanced chemiluminescent substrate (ECL, Amersham Pharmacia Biotech, Inc., Amersham, England) reaction, which was followed by exposing the membranes to hyperfilm ECL.

\section{RNA isolation for microarray analysis}

The hearts and kidneys from non-Tg, Vehicle+dTg, and Dox $+\mathrm{dTg}$ mice were used for the isolation of total RNA using RNAzol (Tel-Test Inc., Friendswood, Texas, USA) according to the manufacturer's instructions. The frozen tissues were minced with scissors and homogenized in RNAzol B solution using a Teflon glass homogenizer. The RNA pellet was suspended in DEPC-treated $\mathrm{dH}_{2} \mathrm{O}$ and purified using a QIAquick purification kit (Qiagen Inc., Chatsworth, CA, USA). The integrity of the 18S/ 28S rRNA was analyzed using a Bioanalyzer 2100 (Quality Agilent Technology Inc., Santa Clara, CA, USA), with the RNA quality checked based on the ratio of absorbance at $260 \mathrm{~nm}$ to that at $280 \mathrm{~nm}$ using a Biophotometer (Hamburg-Eppendorf, Hamburg, Germany). The integrity of each RNA sample was confirmed by $1 \%$ agarose gel electrophoresis, which showed the presence of intact $18 \mathrm{~S}$ and $28 \mathrm{~S}$ ribosomal bands.

cRNA synthesis and labeling were performed using a Chemiluminescent RT-IVT Labeling Kit (Applied Biosystems, Foster City, CA, USA) according to the manufacturer's instruction. Individual samples were submitted in randomly assigned pairs representing tissues from non-Tg and Tg mice. Three micrograms of total RNA was used to synthesize cDNA. Double stranded cDNA was synthesized for $2 \mathrm{~h}$ at $16^{\circ} \mathrm{C}$ in a reaction mixture containing nuclease free water, $5 \times 2^{\text {nd }}$ strand buffer, and $2^{\text {nd }}$ strand enzyme and then purified using a purification column. Finally, the biotinylated cRNA was generated from the cDNA using a BioArray cRNA High Yield RNA Transcript Kit containing purified double stranded cDNA, $5 \times$ IVT buffer Mix, DIG-UTP and IVT enzyme mix.

\section{Microarray analysis}

Changes in global gene expression in the hearts and kidneys of mice overexpressing human $A C E 2$ were analyzed using the Mouse Genome Survey Microarray (Applied
Biosystems) containing oligonucleotide probes for 44, 000 genes. The cRNA was fragmented in fragmentation buffer for $30 \mathrm{~min}$ at $60^{\circ} \mathrm{C}$ prior to chip hybridization. Fifteen micrograms of fragmented cRNA was then added to the hybridization cocktail. Each sample was hybridized to a separate oligonucleotide array for $16 \mathrm{~h}$ at $55^{\circ} \mathrm{C}$ in the GeneChip Hybridization Oven 640. After hybridization, the solution was removed and the slides were washed twice with $2 \times$ SSC containing $0.1 \%$ SDS for $5 \mathrm{~min}$ at $42^{\circ} \mathrm{C}$. The slides were incubated for 20 min with anti-Dig-AP in CL blocking buffer and then developed using the chemiluminescence substrate. Thereafter, the hybridized arrays were scanned using an ABI700 analyzer. Scanning and basic analyses were performed using GenePlex software release 1.0 (ISTECH Inc., Seoul, Korea). Logged gene expression ratios from the fluorescent intensity of each spot were normalized based on regression.

\section{Statistical analysis}

Tests for significance were performed using a one-way ANOVA test of variance (SPSS for Windows, Release 10.01, Standard Version, and Chicago, IL, USA). All values are reported as the mean \pm standard deviation (SD). Microarray data and the statistical significance of differential expression were assessed by hypergeometric distribution analysis. $P$ values less than 0.05 were considered significant.

\section{Results}

\section{Establishment of dTg mice}

First, we produced one male founder mouse carrying the $p \alpha-M H C / r t T A$ construct and one female founder mouse carrying the TRE/hACE2 construct using microinjection techniques. These showed different rates of transgene insertion into the chromosome at 18 and $7 \%$, respectively. Moreover, $\alpha-M H C / r t T A$ and TRE/hACE2 single Tg mice with a BDF2 background were backcrossed with C57BL/6NKorl mice to change their background. During this process, $\alpha-M H C / r t T A$ and TRE/hACE2 constructs were transmitted into the genomes of their offspring of both sexes at a rate of approximately 50\% hemizygous animals based on Mendelian inheritance. Furthermore, both construct genes were transmitted into the genomes of $\mathrm{dTg}$ mice at a $16.3 \%$ efficiency.

Tissue-specific expression of hACE2 during dox treatment To test whether the $h A C E 2$ transgene was expressed under the control of rtTA in a tissue-specific manner, its expression level was detected in various tissues including the brain, heart, lung, liver, kidney, and testis of $\mathrm{dTg}$ mice treated with $2 \mathrm{mg} / \mathrm{mL}$ Dox for 4 weeks. The expression level of $h A C E 2$ was higher in the heart, kidney, and brain than in other organs, although the highest level 

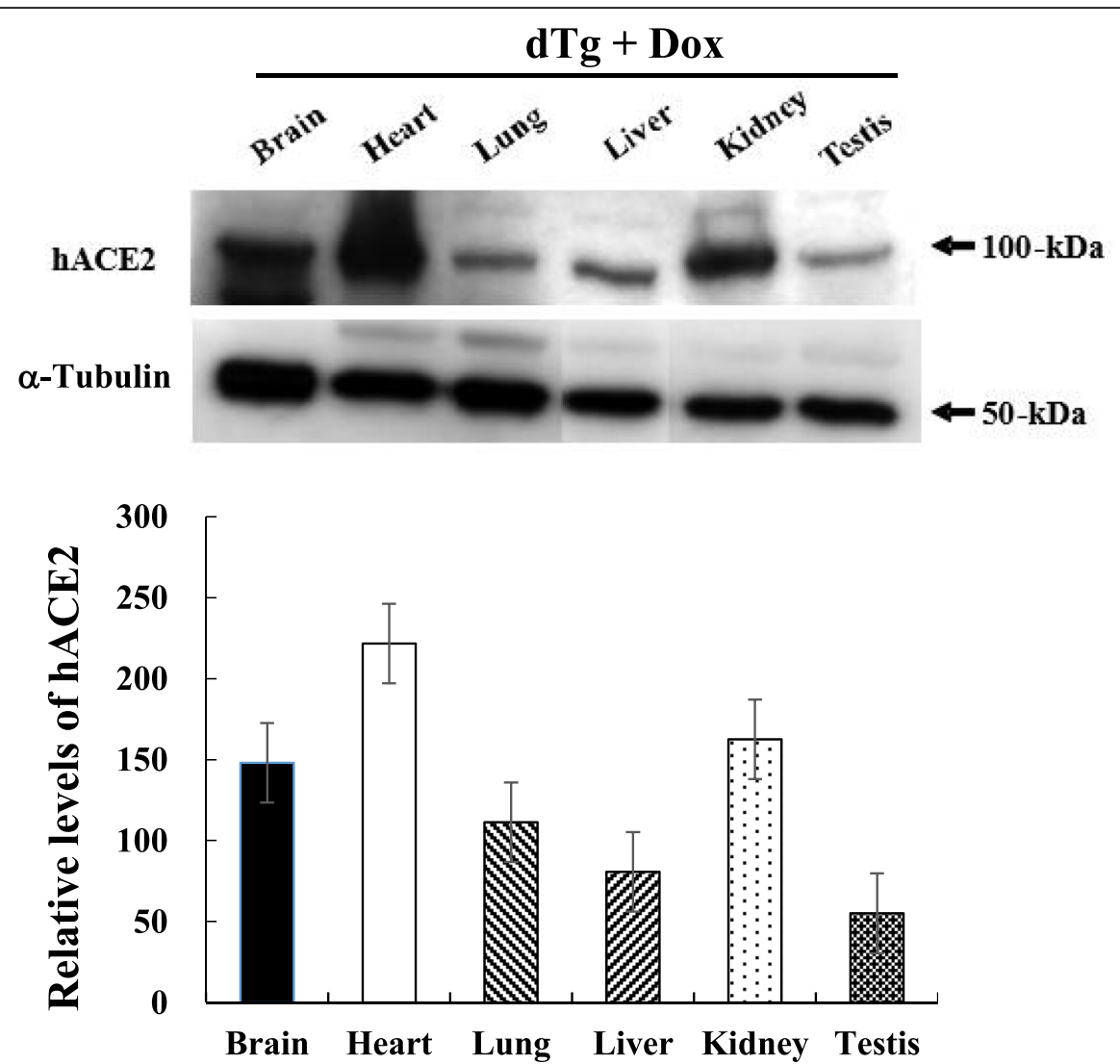

Fig. 2 Human ACE2 (hACE2) levels in organs of double transgenic (dTg) mice treated with doxycycline (Dox). Proteins isolated from the tissues were analyzed by western blotting using an anti-hACE2 antibody, and the a-tubulin signal was used as a control. The density of the protein bands was quantified by Image Station 2000MM. The values represent the mean \pm SD

was detected in the heart. A low level of hACE2 protein expression was observed in the lung, liver, and testis (Fig. 2). However, any significant expression of hACE2 protein was not detected in heart and kidney of non-Tg and C57BL/6 mice (data not shown). Therefore, these results indicate that the hACE2 protein might be successfully expressed in various tissues of $\mathrm{dTg}$ mice through regulation of the Dox-controlled rtTA system.

\section{Comparison of mACE and hACE2 expression in the heart and kidney}

To compare the expression level of mACE and hACE2 proteins in the heart and kidney with or without Dox treatment, both proteins were detected with specific antibodies in these tissues of non-Tg, Vehicle $+\mathrm{dTg}$, and Dox $+\mathrm{dTg}$ mice at the age of 10 weeks. A similar expression pattern for both proteins was observed in the heart and kidney. The hACE2 gene was highly expressed in only Dox $+\mathrm{dTg}$ mice, whereas in non- $\mathrm{Tg}$ and Vehicle $+\mathrm{dTg}$ groups, expression was maintained at low level. However, the expression level of $\mathrm{mACE}$ protein remained constant regardless of hACE2 expression and Dox treatment (Fig. 3a and b). Thus, these results suggest that hACE2 protein can be successfully overexpressed in the hearts and kidneys of dTg mice after Dox treatment. Further, it was suggested that these organs would have great potential for microarray analysis to characterize the changes in global genes during overexpression of the hACE2 protein.

\section{Ontology categories of hACE2-regulated gene expression}

To analyze the differential expression of global genes during hACE2 overproduction in the heart and kidney, microarray data were normalized based on the lowest values obtained from the experiments repeated in triplicate. The normalized log ratios of various genes in each experiment were used to compare relative expression between two independent experiments. Based on these arbitrary differences, a substantial number of genes were expressed at elevated or reduced levels in the $\mathrm{Tg}$ group before and after dox 


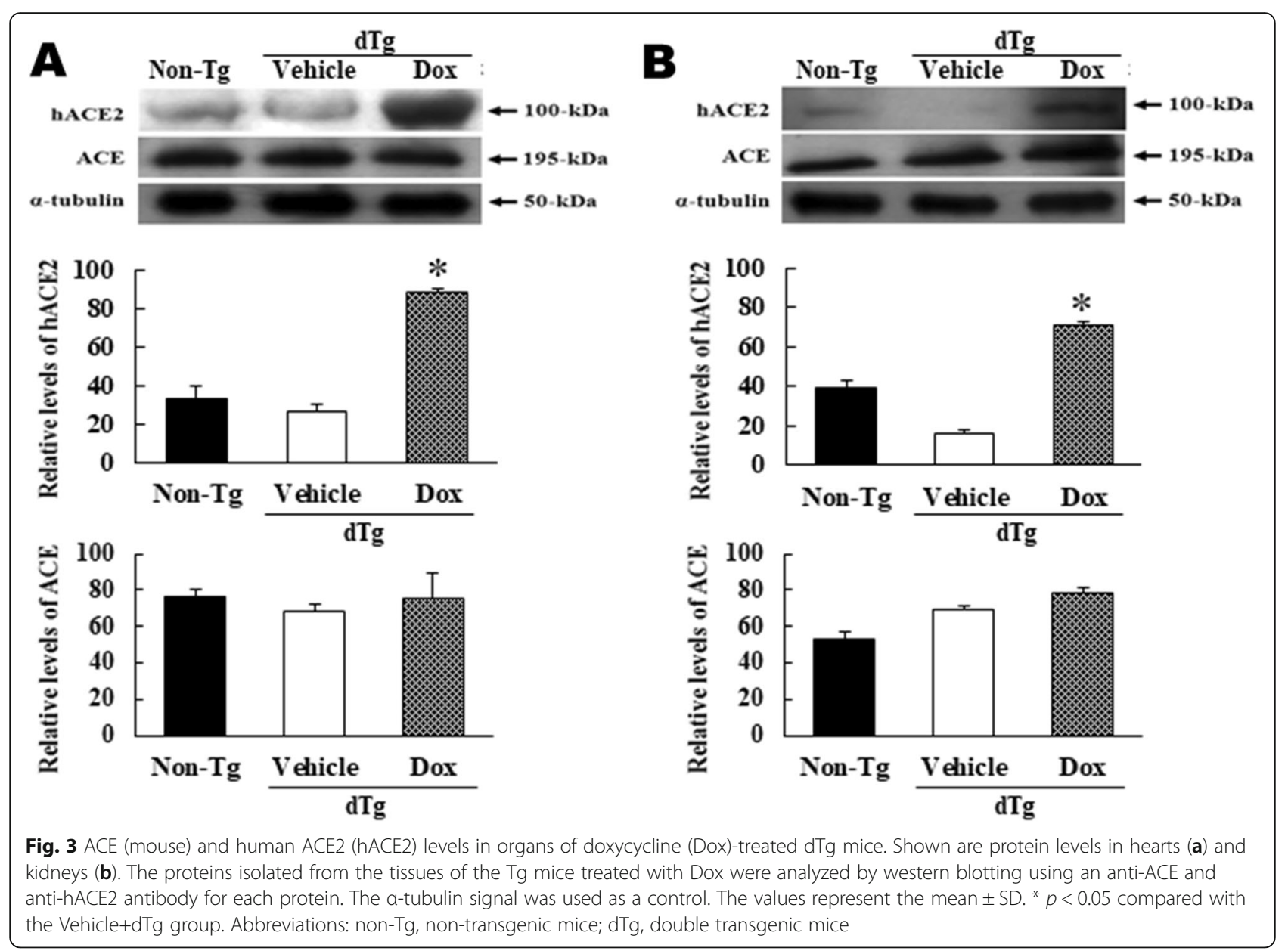

treatment. In the heart, 385 transcripts were selected as differentially expressed genes between non-Tg and Vehicle $+\mathrm{dTg}$ groups based on a 2-fold change in expression, whereas 216 differential transcripts were identified between Vehicle $+\mathrm{dTg}$ and Dox $+\mathrm{dTg}$ groups. Among the former 385 genes, 168 were upregulated and 217 were downregulated in the heart tissue of the $\mathrm{dTg}$ group as compared to levels in the non- $\mathrm{Tg}$ group before Dox treatment. Moreover, 216 genes, including 136 upregulated and 80 downregulated, were differentially expressed in the $\mathrm{dTg}$ group after Dox treatment (Table 1). In the kidney, a total of 402 genes, including 159 upregulated and 243 downregulated genes, were changed in the Vehicle+dTg mice compared to levels in non-Tg mice. Furthermore, after Dox treatment for 4 weeks, 4735 genes, comprising 1636 upregulated and 3109 downregulated, were altered in the dTg group based on a 3-fold change in

Table 1 Summary of differentially expressed genes in Vehicle-treated dTg mice and Dox-treated dTg mice

\begin{tabular}{lll}
\hline Category & Non-Tg vs Vehicle+dTg & Vehicle+dTg vs Dxo+dTg \\
\hline $\begin{array}{l}\text { 44 K Whole Mouse Genome } \\
\text { (Agilent) }\end{array}$ & 44,000 & 44,000 \\
Heart & & Total genes, $n=216$ \\
$\begin{array}{l}\text { Differential expression of known genes at the cut-off } \\
\text { ratio of }>2 \text {-fold }\end{array}$ & $\begin{array}{l}\text { Total genes, } n=385 \\
\text { Upregulated genes, } n=168\end{array}$ & Upregulated genes, $n=136$ \\
Kidney & Downregulated genes, $n=217$ & Downregulated genes, $n=80$ \\
$\begin{array}{l}\text { Differential expression of known genes at the cut-off } \\
\text { ratio of }>3 \text {-fold }\end{array}$ & Total genes, $n=402$ & Total genes, $n=4735$ \\
& Upregulated genes, $n=159$ & Upregulated genes, $n=1636$ \\
Downregulated genes, $n=243$ & Downregulated genes, $n=3109$
\end{tabular}


expression (Table 1). Overall, these results suggest that hACE2 overproduction is more closely related to differentially expressed genes in the kidney than in the heart.

\section{KEGG pathway analysis of hACE2-regulated gene expression}

To analyze the KEGG pathways associated with hACE2regulated gene expression in the heart and kidney of non-Tg and dTg mice based on Dox treatment, GenPlex software release 1.0 was used. The results are presented in Tables 2 and 3. GenPlex identified 15 pathways that were associated with significant changes in the heart (Table 2). As presented in Table 2, the largest numbers of genes in the heart were mainly associated with cytokine-cytokine receptor interaction, the calcium signaling pathway, apoptosis, and ECM-receptor interaction. In the kidney, 17 pathways were identified (Table 3). Especially, genes involved in Wnt signaling were highly changed, followed by those related to oxidative phosphorylation, prostate and colorectal cancer, the TGF-beta signaling pathway, and apoptosis.

Furthermore, we characterized the genes that were downregulated and upregulated by hACE2 overproduction in the hearts and kidneys of Dox $+\mathrm{dTg}$ mice. Of the 136 upregulated genes in the heart, the highest difference was detected for Cap1, followed by Pik3c2g, Syt16, Hecw1, and Tmod2, whereas downregulated genes included calgranulin A, calgranulin B, Paip1, Ptx3, and Hspala. In the kidney, Gabrg1 was associated with the

Table 2 Gene ontology and KEGG pathways related to human ACE2 overexpression in hearts of $\mathrm{dTg}$ mice

\begin{tabular}{lll}
\hline $\boldsymbol{P}$-value & KEGG pathway & $\begin{array}{l}\text { Gene } \\
\text { counts }\end{array}$ \\
\hline 3.70 E-04 & ECM-receptor interaction & 8 \\
$5.55 E-04$ & Metabolism of xenobiotics by cytochrome & 7 \\
& P450 & 6 \\
0.00359981 & Arachidonic acid metabolism & 4 \\
0.01443938 & Type Il diabetes mellitus & 31 \\
0.02960078 & Cytokine-cytokine receptor interaction & 5 \\
0.030258432 & TGF-beta signaling pathway & 4 \\
0.03164412 & Glycolysis / Gluconeogenesis & 4 \\
0.033455342 & Starch and sucrose metabolism & 2 \\
0.049109556 & One carbon pool by folate & 10 \\
0.002257311 & Apoptosis & 4 \\
0.013300485 & Nitrogen metabolism & 14 \\
0.016855394 & Calcium signaling pathway & 2 \\
0.0169800262 & Fatty acid biosynthesis & 8 \\
0.023873353 & Hematopoietic cell lineage & 3 \\
0.03435755 & Amyotrophic lateral sclerosis (ALS) & \\
\hline
\end{tabular}

Mice were treated with doxycycline (Dox) for 4 weeks; $\mathrm{dTg}=$ double transgenic
Table 3 Gene ontology and KEGG pathways related to human ACE2 overexpression in kidneys of $\mathrm{dTg}$ mice

\begin{tabular}{lll}
\hline P-value & KEGG pathway & Gene counts \\
\hline 2.12 E-11 & Oxidative phosphorylation & 97 \\
0.001377066 & Valine, leucine and isoleucine degradation & 35 \\
0.006218532 & Prostate cancer & 78 \\
0.009537098 & One carbon pool by folate & 17 \\
0.017347632 & Glycerolipid metabolism & 34 \\
0.018135441 & Amyotrophic lateral sclerosis (ALS) & 19 \\
0.021784257 & Basal cell carcinoma & 41 \\
0.023491979 & DNA polymerase & 23 \\
0.026797164 & 1- and 2-Methylnaphthalene degradation & 20 \\
0.028321892 & Ubiquinone biosynthesis & 8 \\
0.029679868 & TGF-beta signaling pathway & 67 \\
0.032515198 & Colorectal cancer & 73 \\
0.032849174 & Wnt signaling pathway & 110 \\
0.038628325 & Antigen processing and presentation & 49 \\
0.04013507 & Apoptosis & 65 \\
0.045726832 & Fatty acid metabolism & 29 \\
0.048242938 & Pentose and glucuronate interconversions & 13 \\
\hline
\end{tabular}

Mice were treated with doxycycline (Dox) for 4 weeks; $\mathrm{dTg}=$ double transgenic

highest increase, followed by Wdr66, Ppp1r14c, Bin1, and Mef2c among 1636 upregulated genes, but Slc16a4, Fgfr3, Slc16a10, Stam2, and Mrps2 were significantly decreased after hACE2 overproduction. Taken together, this showed that hACE2 overexpression is mainly associated with cellular pathways related to cytokine-cytokine receptor interactions, the calcium signaling pathway, apoptosis, ECM-receptor interactions, Wnt and TGFbeta signaling, cancer, and oxidative phosphorylation in the hearts and kidneys of dTg mice.

\section{Discussion}

Recently, advances in molecular biology have enabled functional analyses of interesting genes by using transgenic animals and stable cell lines with constant gene expression. However, if the transgene is related to the embryogenesis, the animal might be genetically predisposed to tolerate the effects of the transgene products [34]. To overcome this problem, it is necessary to develop transgenic animals in which transgene expression can be induced at selected time points but kept silent for an extended period. Conditional gene expression has been achieved using a variety of model systems [35, 36]. Non-regulatable promoters in $\mathrm{Tg}$ animals cannot direct the genetic switches to upregulate or downregulate expression from the promoter-linked target gene, and therefore, it is impossible to know how the target gene interacts and regulates the pathophysiological processes at both the basal and inducible level. The Tet-On and 
Tet-Off expression systems are the most widely used inducible regulatory systems. In the Tet-On system, the reverse tetracycline-controlled transactivator (rtTA) acts as an activator of gene transcription [29, 37]. Dox binds the dox-binding site of the rtTA protein, which represents random mutagenesis of the tTA fusion protein between the Tet repressor DNA-binding domain (207 amino acids) and the VP-16 transcriptional activation domain (130 amino acids) of the herpes simplex virus. The dox-rtTA complex then binds the tet sequence, which brings the VP-16 activation domain in close proximity to the minimal human CMV promoter, thereby activating the target gene in the presence of Dox. Indeed, rtTA under the control of the CMV promoter was previously shown to activate the expression of a target gene in various organs $[38,39]$. In this study, the inducible $\mathrm{Tg}$ mice expressing $\alpha$-MHC-controlled, rtTA-regulated hACE2 were generated to address the hypothesis that unregulated expression of the $\mathrm{h} A C E 2$ transgene leads to the generation of defects including cardiac contractile dysfunction, rhythmic disorders, and sudden death. First, single Tg mice expressing $\alpha$-MHC-controlled rtTA and hACE2 were successfully developed by directly introducing each gene into fertilized eggs. Tg mice were mated to induce rtTA-regulated hACE2 expression, which generated founder mice in which hACE2 expression could be increased by Dox. In the established Tg line, neither the location of the transgenes in the genome nor the locus was impacted by gestation or neonatal imprinting. Because of this, all offspring in this experiment exhibited the transmission of $\alpha-M H C / r t T A$ and TRE/hACE2 genes into their genomes in approximately $50 \%$ of hemizygotes.

ACE is considered the central enzyme in the RAS, converting Ang I to Ang II. However, the identification of novel RAS components such as ACE2 and collectrin, a homologue of ACE, capable of degrading Ang II and forming Ang1-7, has emphasized the increasing complexity and multiplicity of biochemical pathways forming the RAS. In a previous study, non-regulatable promoters have been used to create transgenic rats or mice expressing $A C E$ or $A C E 2$ genes under control of the rat cardiac $M L C 2$ or mouse cardiac $\alpha-M H C$ promoter [7, 32]. Unexpectedly, the loss of ACE2 in mice results in profound contractile dysfunction. However, the complete rescue of the heart phenotype in ACE/ACE2double mutant mice indicates that ACE expression has a causative role in the onset of heart dysfunction [25]. Because ACE2 is expressed in the vascular endothelium and not in cardiac myocytes, local increases in Ang II might lead to vasoconstriction, resulting in hyperperfusion and hypoxia in the myocardium. It has been established that Ang II can induce oxidative stress in endothelial cells, and thus, its increase could result in dysfunction of the vascular endothelium via the induction of oxidative stress in the heart $[25,40,41]$. In this study, a heart-specific promoter system was employed to induce rtTA-regulated hACE2 expression at a physiologically relevant site. hACE2 protein was abundantly expressed in heart and kidney tissue of Dox $+\mathrm{dTg}$ mice, although this protein was also detected in several other tissues. These results suggest that the binding of Dox to the rtTA protein might successfully induce hACE2 expression in the heart, kidney, and other organs of $\mathrm{dTg}$ mice. However, any significant histopathological changes was not observed in heart and kidney of Dox $+\mathrm{dTg}$ mice after induction of hACE2 expression for only 4 weeks (Supplement Fig. 1).

Interestingly, the RAS can be seen as a dual function system in which vasoconstrictor or vasodilator actions are primarily driven by the ACE/ACE2 balance [42-44]. Elevated ACE2 activity concomitant with reduced ACE activity leads to a decrease in Ang II levels by converting it into Ang1-7, which in turn promotes vasodilatation [45]. According to this concept, Dox-driven hACE2 expression resulted in a decrease in ACE levels in both hearts and kidneys of Dox-inducible Tg mice compared to that in Non-Tg mice. These results imply that the effects of hACE2 expression, via the formation of Ang1-7, have a counter regulatory role in ACE activity in heart and kidney functions.

The present study also investigated gene profiles to offer critical insight into complexity of the RAS, as well as heart and renal failure related to hACE2 overexpression. Inducible Tg mice overexpressing hACE2 and non$\mathrm{Tg}$ mice were used to address the hypothesis that genes many genes involved in cardiovascular and renal disorders are modulated as compared to levels in Dox $+\mathrm{dTg}$ and Non-Tg mice. The results identified 136 genes from the hearts of Dox $+\mathrm{dTg}$ mice that were significantly upregulated and 80 genes that were downregulated compared to levels in the hearts of Vehicle+dTg mice. A total of 216 genes associated with cellular pathways comprising 15 categories mainly related to ECMreceptor interaction, cytokine-cytokine receptor interaction, apoptosis, the calcium signaling pathway, and the TGF-beta signaling pathway were identified. Of these genes, S100a8 and S100a9, encoding S100 calciumbinding proteins that bind several types of proinflammatory cytokines, such as TNF-alpha, IL-6, and IL1beta, to form the proinflammatory cytokine complex in acute inflammation, play a role in calcium-mediated signaling $[46,47]$. Ptx3, a pentraxin-related gene, is induced in vascular smooth muscle cells via atherogenic modified low density [48] and acts as a nonredundant regulator of tissue damage in acute myocardial ischemia and reperfusion [49]. Thus, these results suggest that the overexpression of hACE2 might be involved in acute 
myocardial infarction and ischemia in the hearts of inducible rtTA-regulated $\mathrm{Tg}$ mice. In the kidney, 1636 genes in Dox-treated $\mathrm{Tg}$ mice were upregulated and 3109 genes were downregulated. These genes were also associated with cellular pathways comprising 17 categories related to apoptosis, the calcium and Wnt signaling pathway, oxidative phosphorylation, cancer, and the TGF-beta signaling pathway. Especially, hACE2 expression was mainly associated with the cellular pathway related to cytokine-cytokine receptor interactions, the calcium signaling pathway, apoptosis, ECM-receptor interactions, Wnt and TGF-beta signaling, cancer, and oxidative phosphorylation, and rtTA-controlled hACE2 expression regulates the expression of genes related to binding, receptor, transferase, oxidoreductase, and hydrolase activities in the hearts and kidneys of $\mathrm{dTg}$ mice. However, our study provides limited information since only mRNA level were analyzed to characterize global gene expression in response to hACE2 overexpression. Furthermore, protein expression analyses and molecular mechanism studies are necessary to conform the effects of identified genes in future study.

\section{Conclusions}

Taken together, we produced rtTA/hACE2 $\mathrm{dTg}$ mice that overexpress the $h A C E 2$ gene based on a Doxinducible system and analyzed the changes in global gene expression in heart and kidney tissue using a microarray. The results of the present study suggest that hACE2 protein was successfully expressed in the heart, kidney, and brain of $\mathrm{dTg}$ mice after Dox treatment. Moreover, our microarray analysis was able to identify several functional groups of genes and individual genes that respond to hACE2 overexpression in the hearts and kidneys of $\mathrm{Tg}$ mice. However, additional work should address the extent to which these changes are correlated with hACE2 expression levels to determine whether beneficial effects can be obtained by reducing expression levels or if the increased expression of ACE2 at any level is deleterious with respect to cardiac and renal disease. Furthermore, it will be necessary to study the functions of differentially expressed genes, which could represent targets for the development of novel drugs, using pharmacoproteomics.

\section{Supplementary information}

Supplementary information accompanies this paper at https://doi.org/10. 1186/s42826-020-00056-y.

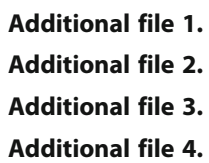

\section{Abbreviations}

ACE2: Angiotensin-converting enzyme 2; MHC: Myosin heavy chain; rtTA: Reverse tetracycline-controlled transactivator; TetR: Tetracyclineresistance operon; TRE: Tet response element

\section{Acknowledgments}

We thank the animal technician, Seon M. Choi, and Mee K. Jang for directing the animal care and use at the Division of Laboratory Animal Resources, NJFDS at Korea.

\section{Authors' contributions}

Conceptualization, S.H.L.; Methodology, S.H.L., S.W.J., and D.Y.H.; Validation, S.H.L. and D.Y.H.; Formal Analysis, S.H.L.; Investigation, S.H.L. and S.W.J; Writing-Original Draft Preparation, S.H.L; Writing-Review \& Editing, D.Y.H., and J.K.K.; Supervision, J.K.K.; Funding Acquisition, D.Y.H. The authors read and approved the final manuscript.

\section{Funding}

This research was supported by a grant from the Laboratory Animal Resources project, Ministry of Food and Drug Safety.

\section{Availability of data and materials}

Available.

\section{Competing interests}

The authors declare that there are no financial conflicts of interest with respect to the publication of these results.

\section{Author details}

${ }^{1}$ Laboratory Animal Resources Division, National Institute of Food and Drug Safety Evaluation, Ministry of Food and Drug Safety, Cheongju 28159, South Korea. ${ }^{2}$ Biologics Division National Institute of Food and Drug Safety Evaluation, Ministry of Food and Drug Safety, Cheongju 28159, South Korea. ${ }^{3}$ Department of Biomaterials Science, College of Natural Resources \& Life Science/Life and Industry Convergence Research Institute, Pusan National University, Miryang 50463, South Korea. ${ }^{4}$ College of Veterinary Medicine, Chungbuk National University, Chungju 28644, South Korea.

Received: 14 April 2020 Accepted: 10 July 2020

Published online: 29 July 2020

\section{References}

1. Donoghue M, Hsieh F, Baronas E, Godbout K, Gosselin M, Stagliano N, et al. A novel angiotensin-converting enzyme-related carboxypeptidase (ACE2) converts angiotensin I to angiotensin 1-9. Circ Res. 2000;87:E1-9.

2. Tipnis SR, Hooper NM, Hyde R, Karran E, Christie G, Turner AJ. A human homolog of angiotensin-converting enzyme. Cloning and functional expression as a captopril-insensitive carboxypeptidase. J Biol Chem. 2000; 275:33238-43.

3. Ferrario CM, Chappell MC, Tallant EA, Brosnihan KB, Diz DI. Counter regulatory actions of angiotensin-(1-7). Hypertension. 1997;30:535-41.

4. Ferrario CM. Angiotension-(1-7) and antihypertensive mechanisms. J Nephrol. 1998;11:278-83.

5. Ribeiro-Oliveira A Jr, Nogueira Al, Pereira RM, Boas WW, Dos Santos RA, Simoese Silva AC. The renin-angiotensin system and diabetes: an update. Vasc Health Risk Manag. 2008:4:787-803.

6. Grobe $J L$, Mecca AP, Lingis M, Shenoy V, Bolton TA, Machado JM, et al. Prevention of angiotensin II-induced cardiac remodeling by angiotensin-(17). Am J Physiol Heart Circ Physiol. 2007;292:H736-42.

7. Doobay MF, Talman LS, Obr TD, Tian X, Davisson RL, Lazartigues E. Differential expression of neuronal ACE2 in transgenic mice with overexpression of the brain renin-angiotensin system. Am J Physiol Regul Integr Comp Physiol. 2007;292:R373-81.

8. Igase M, Strawn WB, Gallagher PE, Geary RL, Ferrario CM. Angiotensin II AT1 receptors regulate ACE2 and angiotensin-(1-7) expression in the aorta of spontaneously hypertensive rats. Am J Physiol Heart Circ Physiol. 2005;289: H1013-9.

9. Hamming I, Timens W, Bulthuis ML, Lely AT, Navis GJ, van Goor H. Tissue distribution of ACE2 protein, the functional receptor for SARS coronavirus. A first step in understanding SARS pathogenesis. J Pathol. 2004;203:631-7. 
10. Valdes G, Neves LA, Anton L, Corthorn J, Chacon C, Germain AM, et al. Distribution of angiotensin-(1-7) and ACE2 in human placentas of normal and pathological pregnancies. Placenta. 2006;27:200-7.

11. Xie X, Chen J, Wang X, Zhang F, Liu Y. Age- and gender-related difference of ACE2 expression in rat lung. Life Sci. 2006;78:2166-71.

12. Burrell LM, Risvanis J, Kubota E, Dean RG, MacDonald PS, Lu S, et al. Myocardial infarction increases ACE2 expression in rat and humans. Eur Heart J. 2005;26:369-75.

13. Goulter AB, Goddard MJ, Allen JC, Clark KL. ACE2 gene expression is upregulated in the human failing heart. BMC Med. 2004;2:19.

14. Gembardt F, Sterner-Kock A, Imboden H, Spalteholz M, Reibitz F, Schultheiss $H P$, et al. Organ-specific distribution of ACE2 mRNA and correlating peptidase activity in rodents. Peptides. 2005;26:1270-7.

15. Tikellis C, Johnston Cl, Forbes JM, Burns WC, Burrell LM, Risvanis J, et al. Characterization of renal angiotensin-converting enzyme 2 in diabetic nephropathy. Hypertension. 2003:41:392-7.

16. Ye M, Wysocki J, William J, Soler MJ, Cokic I, Batlle D. Glomerular localization and expression of angiotensin-converting enzyme 2 and angiotensinconverting enzyme: implications for albuminuria in diabetes. J Am Soc Nephrol. 2006;17:3067-75.

17. Shaltout HA, Westwood BM, Averill DB, Ferrario CM, Figueroa JP, Diz DI, et al. Angiotensin metabolism in renal proximal tubules, urine, and serum of sheep: evidence for ACE2-dependent processing of angiotensin II. Am J Physiol Renal Physiol. 2007;292:F82-91.

18. Chappel MC, Ferrario CM. ACE and ACE2: their role to balance the expression of angiotensin II and angiotensin-(1-7). Kidney Int. 2006;70: $8-10$.

19. Joyner J, Neves LA, Granger JP, Alexander BT, Merrill DC, Chappell MC, et al. Temporal-spatial expression of ANG-(1-7) and angiotensin-converting enzyme 2 in the kidney of normal and hypertensive pregnant rats. Am Physiol Regul Integr Comp Physiol. 2007;293:R169-77.

20. Oudit GY, Imai Y, Kuba K, Scholey JW, Penninger JM. The role of ACE2 in pulmonary diseases--relevance for the nephrologist. Nephrol Dial Transplant. 2009;24:1362-5.

21. Benter IF, Diz DI, Ferrario CM. Pressor and reflex sensitivity is altered in spontaneously hypertensive rats treated with angiotensin-(1-7). Hypertension. 1995;26:1138-44.

22. Turner AJ. Exploring the structure and function of zinc metallopeptidases: old enzymes and new discoveries. Biochem Soc Trans. 2003;31:723-7.

23. Kuba K, Imai Y, Rao S, Gao H, Guo F, Guan B, et al. A crucial role of angiotensin converting enzyme 2 (ACE2) in SARS coronavirus-induced lung injury. Nat Med. 2005;11:875-9.

24. Li W, Moore MJ, Vasilieva N, Sui J, Wong SK, Berne MA, et al. Angiotensinconverting enzyme 2 is a functional receptor for the SARS coronavirus. Nature. 2003:426:450-4.

25. Crackower MA, Sarao R, Oudit GY, Yagil C, Kozieradzki I, Scanga SE, et al. Angiotensin-converting enzyme 2 is an essential regulator of heart function. Nature. 2002;417:822-8.

26. Mahdavi V, Periasamy M, Nadal-Ginard B. Molecular characterization of two myosin heavy chain genes expressed in the adult heart. Nature. 1982;297: 659-64.

27. Subramaniam A, Jones WK, Gulick J, Wert S, Neumann J, Robbins J. Tissuespecific regulation of the alpha-myosin heavy chain gene promoter in transgenic mice. J Biol Chem. 1991;266:24613-20.

28. Gossen M, Bujard $\mathrm{H}$. Tight control of gene expression in mammalian cells by tetracycline-responsive promoters. Proc Natl Acad Sci U S A. 1992;89: 5547-51.

29. Gossen M, Freundlieb S, Bender G, Muller G, Hillen W, Bujard H. Transcriptional activation by tetracyclines in mammalian cells. Science. 1995; 268:1766-9.

30. Zhu Z, Zheng T, Lee CG, Homer RJ, Elias JA. Tetracycline-controlled transcriptional regulation systems: advances and application in transgenic animal modeling. Semin Cell Dev Biol. 2002;13:121-8.

31. Tian XL, Pinto YM, Costerousse O, Franz WM, Lippoldt A, Hoffmann S, et al. Over-expression of angiotensin converting enzyme-1 augments cardiac hypertrophy in transgenic rats. Hum Mol Genet. 2004;13:1441-50.

32. Donoghue M, Wakimoto $H$, Maguire $C T$, Acton S, Hales P, Stagliano N, et al. Heart block, ventricular tachycardia, and sudden death in ACE2 transgenic mice with downregulated connexins. J Mol Cell Cardiol. 2003;35:1043-53.

33. Urlinger S, Baron U, Thellmann M, Hasan MT, Bujard H, Hillen W. Exploring the sequence space for tetracycline-dependent transcriptional activators: novel mutations yield expanded range and sensitivity. Proc Natl Acad Sci U S A. 2000;97:7963-8.

34. Lewandoski M. Conditional control of gene expression in the mouse. Nat Rev Genet. 2001:2:743-55.

35. van der Weyden L, Adams DJ, Bradley A. Tools for targeted manipulation of the mouse genome. Physiol Genomics. 2002;11:133-64.

36. Sun Y, Chen X, Xiao D. Tetracycline-inducible expression systems: new strategies and practices in the transgenic mouse modeling. Acta Biochim Biophys Sin Shanghai. 2007;39:235-46.

37. Welman A, Barraclough J, Dive C. Generation of cells expressing improved doxycycline-regulated reverse transcriptional transactivator rtTA2S-M2. Nat Protoc. 2006;1:803-11

38. Kistner A, Gossen M, Zimmermann F, Jerecic J, Ullmer C, Lubbert $H$, et al. Doxycycline-mediated quantitative and tissue-specific control of gene expression in transgenic mice. Proc Natl Acad Sci U S A. 1996;93: 10933-8.

39. Xu K, Deng XY, Yue Y, Guo ZM, Huang B, Hong X, et al. Generation of the regulatory protein rtTA transgenic mice. World J Gastroenterol. 2005;11: 2885-91.

40. Enseleit F, Hurlimann D, Luscher TF. Vascular protective effects of angiotensin converting enzyme inhibitors and their relation to clinical events. J Cardiovasc Pharmacol. 2001;37:S21-30.

41. Cai H, Harrison DG. Endothelial dysfunction in cardiovascular diseases: the role of oxidant stress. Circ Res. 2000;87:840-4.

42. Warner FJ, Lubel JS, McCaughan GW, Angus PW. Liver fibrosis: a balance of ACEs? Clin Sci (Lond). 2007:113:109-18.

43. Chappell MC. Emerging evidence for a functional angiotensin-converting enzyme 2-angiotensin-(1-7)-MAS receptor axis: more than regulation of blood pressure? Hypertension. 2007;50:596-9.

44. Santos RA, Ferreira AJ. Angiotensin-(1-7) and the renin-angiotensin system. Curr Opin Nephrol Hypertens. 2007;16:122-8.

45. Simoese Silva AC, Pinheiro SV, Pereira RM, Ferreira AJ, Santos RA. The therapeutic potential of angiotensin-(1-7) as a novel renin-angiotensin system mediator. Mini Rev Med Chem. 2006;6:603-9.

46. Ishihara K, Namura T, Murayama H, Arai S, Totani M, Ikemoto M. Possibility of formation of the S100A8/A9-proinflammatory cytokine complexes in vivo in acute inflammation and their functional roles. Rinsho Byori. 2009;57:32431.

47. Leukert N, Sorg C, Roth J. Molecular basis of the complex formation between the two calcium-binding proteins S100A8 (MRP8) and S100A9 (MRP14). Biol Chem. 2005;386:429-34.

48. Klouche M, Peri G, Knabbe C, Eckstein HH, Schmid FX, Schmitz G, et al. Modified atherogenic lipoproteins induce expression of pentraxin-3 by human vascular smooth muscle cells. Atherosclerosis. 2004:175:221-8.

49. Salio M, Chimenti S, De Angelis N, Molla F, Maina V, Nebuloni M, et al. Cardioprotective function of the long pentraxin PTX3 in acute myocardial infarction. Circulation. 2008;117:1055-64.

\section{Publisher's Note}

Springer Nature remains neutral with regard to jurisdictional claims in published maps and institutional affiliations.

Ready to submit your research? Choose BMC and benefit from

- fast, convenient online submission

- thorough peer review by experienced researchers in your field

- rapid publication on acceptance

- support for research data, including large and complex data types

- gold Open Access which fosters wider collaboration and increased citations

- maximum visibility for your research: over $100 \mathrm{M}$ website views per year

At BMC, research is always in progress.

Learn more biomedcentral.com/submission 